Amazonía Peruana, Volumen XVII, No 33, 2020; pp. 29-58

\title{
FORMACIÓN DEL ESTADO, CAPITAL SOCIAL Y MOVILIZACIÓN INDÍGENA EN LA AMAZONÍA PERUANA
}

\author{
Danny Pinedo \\ Universidad Nacional Mayor de San Marcos
}

\section{Resumen}

Este artículo examina la relación entre la formación del Estado y la movilización indígena en la Amazonía peruana. A través de un análisis etnográfico e histórico, se explora cómo los procesos de formación del Estado en la región de Madre de Dios han llevado a los arakbut a establecer complejas interacciones con foráneos. El artículo sostiene que estas relaciones sociales, que se caracterizan no solo por la resistencia sino también por el sometimiento, han configurado las luchas de los arakbut por sus derechos a la tierra. Los recientes compromisos de los arakbut con una multinacional petrolera son influenciados por redes de clientelismo que funcionan como una técnica de gubernamentalidad. Al crear deuda y exacerbar divisiones internas, el clientelismo disciplina a los indígenas, debilitando su resistencia a la explotación petrolera y a otras formas de acción predadora del Estado sobre sus territorios.

Palabras clave: política indígena-formación del Estado-clientelismogubernamentalidad-capital social

\begin{abstract}
This article examines the relationship between state formation and indigenous mobilization in the Peruvian Amazon. Through ethnographic and historical analysis, the article explores how state formation processes in the Madre de Dios region have led the arakbut to complex interactions with outsiders. The article argues that these social relationships, characterized not only by resistance but also by subjugation, have set up the struggles of the arakbut for their rights to the land. The arakbut's recent engagements with an oil multinational company are influenced by clientelism networks that function as a governmentality technique. By creating debt and exacerbating internal divisions, clientelism disciplines indigenous peoples, weakening their resistance to oil exploitation and other forms of predatory state action on their territories.
\end{abstract} capital

Keywords: indigenous politics-state formation-clientelism-governmentality-social 
En octubre del 2009, un grupo de indígenas arakbut subieron a sus botes e iniciaron una travesía de tres días por el río Madre de Dios. Su objetivo era llegar al pequeño pueblo de Salvación y tomar el campamento base de Hunt Oil, una corporación petrolera estadounidense. La manifestación, convocada por la Federación de Comunidades Nativas del Río Madre de Dios y Afluentes (FENAMAD), tenía como propósito obligar a Hunt Oil a poner fin a sus actividades de exploración sísmica en territorio ancestral de los arakbut. En el camino, unos 200 arakbut de varias comunidades ubicadas a lo largo del río se unieron al grupo. Sin embargo, al llegar a la comunidad de Shintuya, los manifestantes no fueron bienvenidos. Los habitantes de Shintuya habían llegado previamente a un acuerdo con Hunt Oil que permitía a la compañía explorar petróleo en las tierras tituladas de la comunidad a cambio de una compensación monetaria. La unidad de las comunidades miembros de FENAMAD contra Hunt Oil se había roto.

El origen de esta historia se remonta al año 1989, cuando los delegados reunidos en un congreso de la FENAMAD propusieron la creación de una reserva comunal como una estrategia para impedir que madereros ilegales entraran a zonas indígenas de caza y pesca que no habían sido incluidas en las tierras tituladas a las comunidades nativas (García 2003). ${ }^{1}$ En el 2002, después de más de diez años de peticiones y manifestaciones masivas organizadas por FENAMAD, el Estado finalmente accedió a crear la Reserva Comunal Amarakaeri para el uso de las comunidades harakbut, matsigenka y yine vecinas a la reserva. Sin embargo, en el 2005 el Estado otorgó a Hunt Oil una concesión para explorar petróleo y gas en el Lote 76, una de las muchas áreas de exploración y explotación de hidrocarburos en las que se ha dividido la región amazónica. Con una superficie de 1434026 hectáreas, el Lote 76 se superpuso a gran parte de la reserva y del territorio de algunas de sus comunidades colindantes. Tanto el Estado como Hunt Oil no consultaron adecuadamente a las comunidades nativas sobre las actividades petroleras dentro de la reserva, a pesar de que la consulta es un mandato del Convenio 169 de la Organización Internacional del Trabajo, del cual el Perú es firmante desde 1994. Además, para facilitar el acceso de Hunt Oil a la reserva, los funcionarios del gobierno hicieron que la zonificación del área protegida fuera más permisiva a la extracción de recursos naturales en áreas ecológicamente sensibles. FENAMAD consideró que la compañía petrolera era una amenaza para la reserva y los medios de subsistencia indígenas que dependen de ella, exigiendo su retiro inmediato. Shintuya y Puerto Luz, sin embargo, discreparon de FENAMAD y permitieron a Hunt Oil ingresar a sus tierras comunales.

1 Las reservas comunales son un tipo de área protegida destinada a conservar la vida silvestre en beneficio de las comunidades nativas y otras poblaciones locales vecinas. Son administradas conjuntamente entre el Estado y las comunidades beneficiarias, pero la propiedad sigue siendo del Estado. Las comunidades nativas son organizaciones corporativas de familias indígenas amazónicas reconocidas oficialmente, con un organismo autónomo y propiedad compartida de la tierra. Aunque en este artículo los términos "comunidad," "asentamiento," y "aldea" se utilizan indistintamente, el término "comunidad nativa" se utiliza solo para referirse a aquellos asentamientos indígenas que han recibido el reconocimiento oficial como tales. 
Esta historia plantea algunas preguntas importantes sobre la organización indígena en la Amazonía y otros contextos latinoamericanos: ¿las tensiones entre las federaciones indígenas y sus comunidades base son intrínsecas a la política indígena? ¿O son el resultado de estrategias de las corporaciones transnacionales para crear división en las organizaciones indígenas? Los indígenas amazónicos tienen una larga historia de interacción con el mundo exterior. Desde el momento en que fueron incorporados por primera vez al Estado-nación peruano, los numerosos pueblos indígenas de la Amazonía han establecido relaciones con una amplia gama de actores estatales y no estatales, incluyendo misioneros, colonos, funcionarios, antropólogos, organizaciones no gubernamentales (ONG) y corporaciones. Sin embargo, en las últimas décadas, el aumento de los precios internacionales de las mercancías, así como la expansión de las industrias extractivas como componente principal de las políticas de desarrollo macroeconómico, han llevado a un aumento tanto en la interacción entre empresas privadas y pueblos indígenas como en la presión para abrir los territorios indígenas a las actividades extractivas.

En este artículo, exploro cómo las recientes respuestas indígenas a la economía extractiva en el departamento amazónico de Madre de Dios son influenciadas por los procesos de formación del Estado y las complejas relaciones sociales a las que estos dan lugar. Demuestro que las interacciones de los indígenas con actores foráneos, que se caracterizan no solo por la resistencia sino también por la subyugación, configuran la capacidad de los pueblos indígenas para movilizarse colectivamente en defensa de sus derechos a la tierra.

En la siguiente sección, discutiré la relevancia de la teoría del capital social para comprender el papel de las relaciones sociales en la movilización política indígena. En esta parte sostengo que para hacer frente a las tensiones internas al activismo indígena, un enfoque centrado en la formación del Estado y las tecnologías de gobierno resulta más productivo que un enfoque sobre la intensidad de la interacción social. Luego analizo los procesos históricos de formación del Estado en Madre de Dios y cómo estos condicionaron la capacidad de los pueblos indígenas no solo de construir capital social sino también de organizarse para la movilización política. En la última sección, examino las recientes relaciones de los indígenas con economías extractivas y la forma en que redes verticales con Hunt Oil operan como una técnica de gubernamentalidad que erosiona la resistencia indígena a la explotación petrolera.

Este artículo se basa en 14 meses de investigación etnográfica que realicé en comunidades arakbut entre el 2011 y el 2012, con una visita de seguimiento en el 2013. ${ }^{2}$ Realicé trabajo de campo tanto en Puerto Maldonado, la capital regional

2 El idioma harakbut tiene varios dialectos, incluyendo el arakbut y el wachiperi. En este artículo, utilizo el término "harakbut" para referirme a todos los grupos que hablan harakbut, y "arakbut" cada vez que hago referencia específica al grupo que habla el dialecto arakbut. Elegí usar las palabras "harakbut" y "arakbut" en lugar de los términos más utilizados "harakmbut" y 
donde se encuentran las oficinas centrales de FENAMAD, como en Puerto Luz, una de las comunidades base de la federación. También hice breves visitas a otras cuatro comunidades base de FENAMAD: San José del Karene, Barranco Chico, Boca Inambari y Shintuya. Los datos etnográficos se recopilaron mediante entrevistas semiestructuradas y observación participante intensiva, mientras que los datos históricos se basan en entrevistas de historia oral, fuentes de archivo y literatura publicada sobre el área.

\section{Capital social, formación del Estado y gubernamentalidad}

El concepto de capital social proporciona un marco teórico a partir del cual se puede discutir el aparente fracaso de FENAMAD para mantener unidas a sus bases durante el conflicto con Hunt Oil. Desde un enfoque económico, el capital social es definido como las redes sociales, las normas compartidas de reciprocidad y la confianza que permiten la acción colectiva (Coleman 1988; Putnam, Leonardi y Nanetti 1993). Así entendido, el capital social facilitaría la interacción, alentaría la obligación mutua y proporcionaría sanciones a la deserción, creando confianza en el proceso. La confianza, a su vez, reduce los costos de transacción de la cooperación, asegurando el cumplimiento de las normas sociales (Coleman 1988). El capital social no solo es susceptible de convertirse en otras formas de capital, sino que, una vez creado, actúa como un "bien público" del que todos podrían beneficiarse, incluso aquellos que inicialmente no contribuyeron a su creación (Coleman 1988). El capital social podría facilitar una acción colectiva efectiva no solo a nivel comunitario, sino también a nivel nacional, donde explicaría la presencia del desarrollo económico y la gobernanza democrática (Putnam, Leonardi y Nanetti 1993). Por lo tanto, la ausencia de acción colectiva, democracia o prosperidad económica puede verse como resultado de la incapacidad de las comunidades y las naciones para acumular "reservas" de capital social.

El capital social es también considerado crucial para los movimientos sociales. Los estudiosos de los movimientos indígenas latinoamericanos, en particular, sugieren que el capital social fortalece la capacidad de las organizaciones indígenas para ayudar a sus bases a obtener acceso a derechos y recursos (Bebbington 1997; Bebbington y Perreault 1999; Perreault 2003). Al capital social -en forma de comunidades, organizaciones de base federadas, redes con actores no locales e identidad compartida- se le atribuye el rol de fortalecer la capacidad de negociación y de facilitar el acceso a títulos de propiedad, educación, crédito, infraestructura, proyectos de desarrollo y nuevos mercados, contribuyendo así al mejoramiento y sostenibilidad de los medios de sustento.

Uno podría asumir que debido a que los indígenas en Madre de Dios tienen una vida asociativa densa, expresada en la existencia de una federación indígena de

"arakmbut", porque representan mejor la fonética del idioma harakbut. Esta nueva ortografía ha sido reconocida por el Ministerio de Educación y es como los harakbut prefieren ser llamados. 
nivel regional y 37 comunidades nativas afiliadas a ella, poseen grandes cantidades de capital social y, por lo tanto, disfrutan de altos niveles de acción colectiva. De hecho, la evidencia no siempre muestra que es así. A pesar de que la región tiene una vibrante historia de organización indígena, los indígenas siguen siendo pobres, la acción colectiva en las comunidades es débil e intermitente y FENAMAD sufre de tensiones internas recurrentes. Esto plantea preguntas sobre la efectividad de las organizaciones indígenas en Madre de Dios: ¿Las dificultades de FENAMAD para mantener la lealtad de sus bases es el resultado de las dificultades que los pueblos indígenas enfrentan para construir lazos de solidaridad duraderos entre las comunidades y entre estas y la federación? ¿O es más bien un ejemplo de la incapacidad del capital social existente para brindar amplios beneficios a los pueblos indígenas? Una discusión de las limitaciones de la perspectiva economicista del capital social nos proporcionará un marco teórico para abordar estas cuestiones.

A pesar de su gran influencia en los ámbitos tanto académico como del desarrollo internacional, el enfoque económico del capital social no está exento de dificultades analíticas. Los críticos de esta perspectiva han señalado su incapacidad para distinguir entre diferentes formas de capital social y las cantidades variables de bien público que pueden derivarse de ellas (Fine 1999; Harriss y de Renzio 1997). Los defensores del capital social tienden a enfocarse en las organizaciones formales o a ver las diferentes organizaciones como iguales expresiones de capital social o que solo tienen efectos positivos. Sin embargo, en la vida real, las personas se involucran en diversas relaciones y asociaciones que podrían diferir en sus efectos sociales. Los críticos hablan de un "lado negativo" del capital social, como en el caso de las organizaciones criminales o terroristas cuyas actividades ilegales también dependen de redes sociales (Landolt y Portes 1996). Aun así, otros han distinguido entre lazos afectivos o "fuertes" (por ejemplo, redes basadas en el parentesco y la etnicidad) y lazos de conexión o "débiles" (redes transversales), y afirman que si bien los primeros fortalecen la solidaridad dentro de grupos pequeños, los segundos traen cohesión social a la sociedad en general (Granovetter 1973; Holzner 2004; Narayan 1999).

Pierre Bourdieu (1986) llamó la atención sobre una de las limitaciones teóricas más importantes en las visiones dominantes del capital social: su falta de atención a las dimensiones materiales, simbólicas y políticas de las redes sociales. Como los individuos y los grupos están socialmente diferenciados, el capital social tiende a distribuirse de manera desigual y, por lo tanto, a reproducir las desigualdades sociales (Bourdieu 1986). Algunos grupos pueden tener más poder que otros para construir capital social y convertirlo en otras formas de capital, especialmente capital económico (Mosse 2006). La necesidad de capital económico puede obligar a los pobres a participar en redes altamente desventajosas con los ricos, en cuyo caso el capital social puede usarse para dominar y explotar. Además, los legados históricos de las relaciones horizontales son necesarios pero no suficientes para garantizar la formación de capital social. La estructura de oportunidad política 
puede condicionar la capacidad de lazos y organizaciones horizontales para formar redes de alianzas (Fox 1996). Un enfoque bourdieusiano cuestiona los fundamentos teóricos del modelo economicista del capital social y su énfasis en actores racionales que ven las relaciones sociales y las organizaciones como un recurso para lograr beneficios individuales y colectivos. Aquí abogo por una visión antropológica del capital social que se centra en las relaciones sociales, los significados y la moralidad que impulsan a las personas y a los grupos a conectarse (McNeill 2007), así como en las estructuras de poder que limitan las redes y asociaciones o condicionan su poder y alcance (Mosse 2006); un enfoque que explica mejor las complejidades y ambigüedades del capital social.

Desde su contacto con la sociedad nacional, los arakbut se han involucrado en diversas redes con poderosos actores foráneos. Estas relaciones sociales han tenido diferentes efectos sobre la capacidad de los arakbut para organizar colectivamente la defensa de sus derechos territoriales. Si bien los lazos transversales han permitido a los arakbut obtener recursos y formar organizaciones, los lazos afectivos a menudo han fomentado el faccionalismo entre ellos. En las últimas décadas, la exclusión estructural de los derechos, recursos y oportunidades fundamentales ha obligado a los indígenas amazónicos a entablar lazos afectivos, especialmente el clientelismo, con actores corporativos para obtener acceso a recursos, una situación que inhibe la capacidad de los indígenas para construir confianza y cooperación. En su significado antropológico, el clientelismo (también conocido como patronazgo y relaciones patrón-cliente) se refiere a relaciones recíprocas entre actores (individuos o grupos) de poder desigual, a través de las cuales el actor poderoso (o patrón) proporciona al débil (o cliente) ayuda y protección económica, mientras que el cliente responde con servicios y apoyo político para el patrón (Weingrod 1968). ${ }^{3}$ Este artículo busca demostrar que las redes clientelares entre Hunt Oil y los arakbut producen efectos antisociales (divisiones internas y pobreza) que socavan su capacidad para enfrentar las desventajas de la explotación petrolera.

Las dimensiones económicas, políticas y culturales de las redes sociales se pueden entender mejor si se analizan como resultado de los procesos de formación del Estado. En las últimas décadas, los antropólogos han vuelto a interesarse en el estudio del Estado, cuestionando la idea del Estado como un aparato centralizado, unificado y claramente delimitado que concentra el poder sobre la sociedad y se construye independientemente de la sociedad y por encima de ella (Ferguson y Gupta 2002; Gupta 1995). Estos autores sugieren que el Estado debería entenderse más bien como un proceso inconcluso y disputado que solo puede ser estudiado a través del análisis de contextos locales informados histórica y etnográficamente (Das y Poole 2004; Krohn-Hansen y Nustad 2005). Desde esta perspectiva, no existe un límite

3 Este significado contrasta con el utilizado por los politólogos, que definen el clientelismo como las formas en que las autoridades y los partidos políticos intercambian obras públicas y otros favores especiales por apoyo electoral (Weingrod 1968). 
claro entre el Estado y la sociedad, ya que el Estado puede alinear sus intereses con los de entidades no estatales y estas últimas pueden asumir funciones del primero. Esta idea se aplica bien a la Amazonía peruana. El carácter de la Amazonía como una región fronteriza, con una aparente ausencia o debilidad del Estado, no configura una situación de vacío de poder, porque el gobierno ha sido ejercido por caucheros, misioneros, colonos y, más recientemente, corporaciones mineras y petroleras. La promoción de la colonización, el establecimiento de misiones y el otorgamiento de concesiones de caucho y petróleo han sido particularmente importantes para que el Estado aproveche nuevos recursos naturales, reclame la soberanía sobre los territorios disputados por los países limítrofes e incorpore pueblos indígenas a la economía de mercado. La formación del Estado también implica la creación de subjetividades específicas que le permiten al Estado controlar a las poblaciones, generalmente ordenando a los sujetos en categorías y obligándolos a conformarse a ellas (Scott 1998; Baitenmann 2005). En este artículo, sugiero que la construcción de nuevas formas de gobierno en Madre de Dios ha condicionado la capacidad de los arakbut para construir redes sociales y la naturaleza de estas redes.

En las últimas décadas, las tecnologías de la gubernamentalidad neoliberal se han convertido en la forma dominante de gobierno. A partir de la idea de "gubernamentalidad" de Foucault (1991), Ferguson y Gupta (2002) han acuñado el término "gubernamentalidad transnacional", por el cual se refieren a la transferencia de funciones de gobierno a agencias transnacionales no estatales y a la producción de nuevas subjetividades que han tenido lugar con el advenimiento del neoliberalismo. La gubernamentalidad neoliberal se logra a través de la reestructuración del gobierno estatal hacia la autodisciplina (o "tecnologías del yo"). La subjetividad neoliberal está guiada por una racionalidad del mercado que representa a los sujetos como empresas corporativas cualificadas y amorales, capaces de tomar decisiones autónomas, correr riesgos, asumir responsabilidades y construir alianzas con otros actores corporativos, todo lo cual alienta a los sujetos a disciplinarse (Gershon 2011; Lemke 2001; Rose 1996). Un ejemplo del consentimiento de las comunidades a la subjetividad neoliberal en América Latina es su compromiso con las corporaciones bajo el discurso moral de la responsabilidad social corporativa (RSC), según lo cual las relaciones de patronazgo con las corporaciones se consideran "asociaciones" que distribuyen equitativamente la responsabilidad y los riesgos (Babidge 2013). Desde los años noventa, el Estado peruano ha abrazado fuertemente políticas neoliberales que alentaron el repliegue del Estado de su papel en la promoción del desarrollo, así como la externalización de esta función estatal a empresas transnacionales. En este contexto, las relaciones de los arakbut con corporaciones multinacionales pueden entenderse como determinadas por tecnologías de gobierno neoliberal que han erosionado la capacidad de los indígenas para moldear las relaciones con los foráneos en sus propios términos. Las redes clientelares que algunos arakbut han construido con Hunt Oil han funcionado como un mecanismo gubernamental que disciplina a los arakbut, al volverlos dependientes de la corporación y generar tensiones dentro de las comunidades y entre ellas. 


\section{Estado y relaciones sociales en Madre de Dios}

La región de Madre de Dios permaneció aislada durante gran parte de la historia colonial y republicana del Perú. No fue hasta el auge del caucho (18801920) que el Estado peruano comenzó a incorporar esta región y a sus pueblos indígenas. La población de los primeros grupos harakbut en ser contactados fue diezmada. Sin embargo, los arakbut lograron refugiarse en áreas remotas hasta que finalmente fueron contactados por misioneros dominicos y del Instituto Lingüístico de Verano (ILV) a fines de la década de los cincuenta. En ese momento, la región estaba débilmente conectada con el resto del país, principalmente debido a que el Estado carecía de los recursos para promover una colonización a gran escala y proveer infraestructura vial. En este contexto, los misioneros fueron instrumentales para los intereses del Estado, ya que jugaron un papel clave en la pacificación de los indígenas, cuya resistencia amenazaba la expansión de la colonización y la prospección de recursos.

Los dominicos llevaron a cabo su trabajo de proselitismo en estaciones misionales, donde los arakbut experimentaron cambios en su organización social y patrones de consumo. Los misioneros usaron la entrega de regalos, especialmente de herramientas de metal y medicinas, para contactar y luego atraer a los arakbut a las misiones. Cientos de indígenas, algunos de ellos enemigos entre sí, fueron concentrados en puestos misionales, lo que provocó que sus malocas (casas comunales) tradicionales se dividieran en grupos más pequeños (Fuentes 1982: 167; Torralba 1979). Esto, a su vez, generó tensiones y un realineamiento de las relaciones de poder entre los indígenas, pues aquellos grupos más cercanos a los misioneros ganaron poder. Para evitar ser ridiculizados por grupos indígenas aculturados, los arakbut abandonaron el uso de las malocas y la práctica de rituales de pubertad (Moore 1979). Además, los dominicos desarrollaron relaciones de peonaje por deuda con los indígenas para estimular su dependencia sobre bienes occidentales y retenerlos como mano de obra. El peonaje por deuda es una forma coercitiva de reclutamiento y retención de mano de obra que se basa en el adelanto de bienes y en la deuda que genera, que luego se paga con trabajo. Se convirtió en una forma generalizada de reclutar mano de obra indígena en la Amazonía luego de que la explotación del caucho, y las prácticas de esclavización en las que se basó, llegara a su fin. En la misión de Shintuya, por ejemplo, los dominicos controlaban el acceso a bienes (ropa), servicios (escuela, centro de salud) y trabajo en la explotación forestal, ganadería y cultivo de café, actividades en las que se sustentaba la economía de la misión. Incluso decidían con quién podían casarse los indígenas. Los misioneros otorgaban acceso a recursos y mujeres solo a aquellos individuos que se comportaban de acuerdo con los preceptos cristianos y mostraban obediencia (Wahl 1987: 259). Los misioneros también absorbían las ganancias de la misión y comercializaban los excedentes que los indígenas producían, manteniendo al mínimo la interacción indígena con comerciantes, traficantes y otros representantes de la sociedad nacional. Así, al evitar que los 
indígenas desarrollaran relaciones autónomas con los foráneos, los misioneros aseguraban para sí el ventajoso papel de intermediarios.

Atrapados en relaciones de peonaje por deuda con los misioneros, los arakbut no podían alzarse contra las condiciones de explotación a las que estaban sujetos en la misión. Estas condiciones sociales fueron similares a las relaciones paternalistas que los hacendados establecieron con los campesinos en la sierra peruana y otras regiones latinoamericanas. Los siervos indígenas de la hacienda obtenían acceso a la tierra y otros recursos a través de relaciones interpersonales con el patrón, no con otros campesinos, un sistema cerrado que el sociólogo Julio Cotler describió como un "triángulo sin base" (Cotler 1969). Como el sistema les impedía comunicarse entre sí, los peones de hacienda se mantenían socialmente fragmentados, incapaces de levantarse contra el patrón. Del mismo modo, en Shintuya, el peonaje por deuda generó competencia entre los indígenas por el acceso a los recursos y las mujeres, lo que finalmente generó resentimiento entre los que salían perdiendo (Gray 1996: 252; Wahl 1987: 272-3). Según mis informantes, en lugar de agresión hacia los misioneros, estas tensiones se expresaron a través de la acusación de brujería y el asesinato entre los indígenas.

Para evitar el peonaje por deudas con los misioneros, entre 1969 y 1974, los arakbut huyeron progresivamente de Shintuya y retornaron a sus territorios tradicionales, donde se reagruparon en nuevos asentamientos. ${ }^{4}$ Lejos del papel mediador de los misioneros, los arakbut pudieron establecer nuevamente alianzas matrimoniales entre grupos de parentesco, tanto dentro como fuera de sus asentamientos recientemente formados. También tuvieron la libertad de entablar relaciones independientes con colonos mineros provenientes de las cercanas serranías andinas. Un creciente número de campesinos andinos empobrecidos, empujados por la pérdida de sus tierras a manos de los hacendados, venía migrando a territorio de los arakbut desde principios de los años sesenta, estableciéndose alrededor de yacimientos auríferos que eran pobremente regulados por el Estado. ${ }^{5}$ Mis entrevistas sugieren que las relaciones entre los arakbut y los colonos mineros eran tan importantes como aquellas entre grupos de parentesco arakbut. Los arakbut aprendieron de los colonos cómo lavar el oro aluvial, una actividad que pronto se convertiría en la base de su sustento y en la fuente de ingresos que los arakbut necesitaban para adquirir los bienes y servicios de los que dependían cada vez más desde los tiempos de la misión. A pesar de ser económica y políticamente menos poderosos, los arakbut pudieron conservar el control de sus territorios y mantener sus relaciones con los colonos mineros en términos de una reciprocidad

4 Un grupo de malocas arakbut permaneció en Shintuya solo por un año (entre 1962 y 1963), después de lo cual los arakbut huyeron y formaron el asentamiento de Puerto Alegre, donde permanecieron bajo la influencia de misioneros del ILV. Posteriormente, los arakbut de Puerto Alegre se mudaron a su actual emplazamiento, conocido hoy como Puerto Luz.

5 Si bien la extracción de oro en la Amazonía requería de una concesión otorgada por el Estado, en la práctica cualquiera podía apropiarse de facto de un placer de oro. 
bastante simétrica. En Boca Inambari, por ejemplo, los arakbut permitieron a los colonos extraer oro de su territorio a cambio de equipos de minería, lo que facultó a los arakbut practicar esta actividad de manera independiente. Romper el rol de los misioneros como únicos mediadores con el sistema socioeconómico más amplio, por lo tanto, representó para los arakbut la posibilidad no solo de evitar las claramente explotadoras relaciones de peonaje por deuda, sino también de recuperar el control de sus territorios, de forjar relaciones independientes con foráneos y de participar de manera autónoma en la economía de mercado a través de la minería aurífera.

Sin embargo, estos procesos de integración social tuvieron sus limitaciones. Mis entrevistas indican que a medida que la población de Puerto Luz creció, aumentaron las tensiones entre las familias, lo cual llevó a la división de la aldea en varios grupos familiares (o grupos de residencia). ${ }^{6}$ La minería aurífera, que se practicó primero mediante la agrupación de varias unidades domésticas, se convirtió en una actividad familiar, al igual que la mayoría de las actividades realizadas por las altamente autosuficientes unidades domésticas arakbut. Además, las grandes distancias geográficas que separaban a los nuevos asentamientos arakbut dificultaron que los arakbut establecieran redes de alianza más amplias.

Las características de la formación del Estado en la Amazonía hacia finales de la década de los sesenta facilitaron aún más la participación de los arakbut en la economía del oro. Entre fines de la década de los sesenta y principios de la de los setenta, el gobierno militar del general Juan Velasco Alvarado implementó políticas de modernización de corte izquierdista que implicaron un mayor control del Estado sobre los sectores industrial, financiero y de servicios (Lowenthal 1975). En Madre de Dios, esta nueva política se tradujo en un mayor control estatal de la minería aurífera, que hasta entonces había permanecido bastante desregulado. Entre 1972 y 1974, después de un aumento significativo en el precio internacional del oro, el régimen militar abrió en la región varias agencias del Banco Minero, que monopolizó la comercialización del oro y suministró a los mineros herramientas, alimentos y otras provisiones a precios subsidiados (Moore 1979). El gobierno también suspendió el otorgamiento de concesiones mineras, reemplazándolas con permisos concedidos a un número limitado de mineros que habían sido previamente registrados por el Banco Minero (Pacuri y Moore 1992). Este aumento de la regulación estatal de la extracción de oro mantuvo bajo control el número de mineros entrantes y la competencia con los arakbut por los placeres de oro. La imposibilidad de competir con los precios más bajos del Banco Minero impidió a los comerciantes y mineros foráneos posicionarse como patrones (Moore 1979; Pacuri y Moore 1992). La ausencia de patrones que pudieran reemplazar el papel desempeñado anteriormente por los misioneros, así como la provisión de suministros de minería baratos por parte del Banco Minero, facilitaron la incorporación de la minería aurífera a la economía de los arakbut.

6 La fisión social como estrategia para el manejo de conflictos internos es una práctica común entre los arakbut y otros pueblos indígenas amazónicos. 
La administración de Velasco también implementó reformas corporativas que tuvieron un impacto importante en los indígenas amazónicos. A través de la creación en 1971 del Sistema Nacional de Apoyo a la Movilización Social (SINAMOS), el régimen militar buscó obtener el apoyo de las clases populares y cooptar su participación política. Durante la primera mitad de la década de los setenta, SINAMOS apoyó la formación de varias federaciones indígenas en la Amazonía (Morin 1992). Asimismo, en el contexto de su radical reforma agraria, el gobierno promulgó en 1974 la Ley de Comunidades Nativas, que reorganizó los asentamientos indígenas en comunidades nativas a la vez que alentó el desarrollo agrícola y la colonización en la Amazonía. ${ }^{7}$

El presidente Velasco fue derrocado en 1975 por el general Francisco Morales Bermúdez, cuyo gobierno (1975-1980) marcó un cambio hacia políticas liberales y de privatización (Dean 2002: 211). Más interesado en abrir los bosques amazónicos a las corporaciones privadas, el nuevo gobierno recortó drásticamente los fondos estatales para la titulación de tierras de las comunidades nativas. Además, durante el gobierno de Morales Bermúdez se promulgó una nueva ley de minería que eliminó el monopolio del Banco Minero sobre el comercio del oro y restableció el otorgamiento de concesiones mineras a empresas privadas. Como resultado, casi todas las tierras reclamadas por los arakbut fueron solicitadas como concesiones por mineros medianos y grandes compañías mineras nacionales y transnacionales. Además, debido a un nuevo aumento en el precio internacional del oro a principios de la década de los ochenta, los colonos mineros comenzaron a llegar por millares a territorio arakbut. Todo esto provocó que el oro fuera extraído a una escala nunca antes vista. Ni los pequeños colonos mineros ni los arakbut pudieron obtener concesiones mineras debido a los engorrosos y costosos trámites, que obligaron a los colonos mineros a trabajar para los titulares de grandes concesiones o a invadir tierras indígenas (Moore 1983; Pacuri y Moore 1992). Las relaciones entre los colonos mineros y los arakbut dejaron de ser recíprocas. Muchas comunidades arakbut vieron sus territorios invadidos también por corporaciones mineras.

Los arakbut buscaron la titulación como una estrategia para defender legalmente sus tierras comunales. Sin embargo, para 1980, ninguna de las comunidades arakbut había sido titulada, pues la titulación era y sigue siendo un proceso largo, complicado y costoso. Los arakbut tampoco pudieron usar el sistema judicial para desalojar a los intrusos, pues las corporaciones y los colonos, económica y políticamente más poderosos, se coludían con las autoridades y lograban hacer prevalecer sus propios intereses. Por lo tanto, los arakbut no tuvieron más remedio que tomar sus arcos y flechas y expulsar físicamente a los invasores de sus tierras,

$7 \quad$ Una de las leyes para pueblos indígenas más progresistas de su tiempo, la Ley de Comunidades Nativas de 1974 otorgó a los indígenas amazónicos derechos de propiedad sobre las tierras agrícolas y los bosques. Sin embargo, el subsuelo y los recursos hídricos se mantuvieron como propiedad del Estado. 
lo que condujo a una serie de violentos altercados con los colonos y los trabajadores de las compañías mineras.

Sin embargo, la movilización comunitaria era altamente dependiente de la percepción de una amenaza externa. Ya sea si se tratara de restaurar el tejido social dañado en las misiones o de obtener títulos de tierras, la formación de comunidades produjo un capital social basado en redes afectivas más que en redes transversales. Los lazos sociales y solidaridades así creados fortalecieron las conexiones al interior de los grupos de residencia y entre algunas familias arakbut y colonos mineros (Pinedo 2014). Si bien estas redes sociales ayudaron a los arakbut a recuperar la viabilidad social y obtener acceso a capital económico, fueron menos efectivos para fomentar los vínculos entre grupos de residencia, comunidades y pueblos indígenas. Además, la movilización colectiva para obtener títulos de propiedad impulsó la formación de identidades comunitarias dentro de los asentamientos arakbut, lo que exacerbó las antiguas rivalidades étnicas entre malocas y pueblos indígenas (Pinedo 2019).

Así, se hizo más evidente que la defensa de los territorios arakbut requeriría forjar alianzas más amplias y permanentes entre las comunidades. Esto ya había sucedido en otras partes de la Amazonía peruana, donde la creación de federaciones indígenas fue posible gracias a la formación de comunidades, un proceso que mejoró la comunicación, la solidaridad y la cooperación entre los asentamientos indígenas basados en el parentesco (Veber 1998). Sin embargo, la distancia geográfica entre los asentamientos arakbut y las antiguas rivalidades y tensiones étnicas entre ellos y otros pueblos indígenas fueron obstáculos importantes para la organización y la movilización. Además, los arakbut no tenían experiencia previa en la formación de organizaciones más allá del grupo residencial ni fondos para llevarla a cabo. En este contexto, las redes con foráneos fueron especialmente importantes para obtener los recursos que los arakbut requerían para establecer organizaciones capaces de movilizar a varias comunidades.

La dictadura de Morales Bermúdez fue propicia para la creación de estas redes. El gobierno no solo redujo los fondos para la titulación de tierras comunales, sino que también cerró SINAMOS en 1978, lo que marcó el final de la intervención estatal en la organización popular (Yashar 2005: 236). Esta coyuntura política favoreció la proliferación de actores de la sociedad civil que asumieron el papel del Estado en el apoyo a los indígenas para obtener títulos de propiedad y formar organizaciones para la defensa de sus derechos. Por ejemplo, un grupo de antropólogos que había trabajado para SINAMOS fundaron el Centro de Investigación y Promoción Amazónica (CIPA), una ONG que en 1979 ayudó a cuatro asentamientos harakbut a demarcar sus tierras comunales (Rummenhoeller, Cárdenas, y Lazarte 1991). Además, Thomas Moore, un antropólogo estadounidense, apoyó a los arakbut para asegurar recursos financieros y personalmente les brindó asistencia técnica para formar FENAMAD en 1982. Durante esos años, se desarrollaron procesos similares 
de construcción de redes indígenas con ONG y activistas de los derechos indígenas en otras partes de la Amazonía peruana y en otros contextos latinoamericanos (ver, por ejemplo, Brysk 2000 y Greene 2006).

FENAMAD pronto se convirtió en un centro de redes que contribuyó a construir identidad y lazos de solidaridad entre sus comunidades base. Yashar (2005: 246) ha señalado que la violencia política asociada con los movimientos guerrilleros de los años ochenta y principios de los noventa disminuyó la capacidad de los pueblos indígenas de formar redes y asociaciones políticas. Si bien el impacto de la violencia de la guerrilla fue menos generalizado en Madre de Dios que en otras partes de la Amazonía peruana, los arakbut aún tuvieron que enfrentar la hostilidad del gobierno hacia la movilización indígena. Mis informantes me dijeron que mientras se dirigían desde sus comunidades a Puerto Maldonado, los arakbut eran a menudo detenidos en los puestos de control militar por no contar con documentos de identidad o permisos de conducir para sus embarcaciones. En este contexto, el trabajo de FENAMAD y sus aliados proporcionó las condiciones necesarias para la construcción de lazos intercomunitarios. Al reunir constantemente a los jefes de las comunidades, que de otro modo no habrían tenido mayor contacto, la federación mejoró la comunicación entre comunidades distantes y facilitó la toma de decisiones colectivas. Por otra parte, la federación convocó, financió y lideró protestas en forma de huelgas, marchas y manifestaciones en Puerto Maldonado, en las que miembros de las comunidades tuvieron participación activa. La intervención en estas reuniones y protestas permitió a los pueblos indígenas dejar de lado, al menos temporalmente, sus rivalidades étnicas, haciendo posible la existencia de FENAMAD como una federación multiétnica.

FENAMAD no solo contribuyó a construir redes entre las comunidades, sino también ayudó a los indígenas a romper su dependencia de los patrones locales y a eludir las relaciones de patronazgo con el Estado. A diferencia de casos en que los misioneros alentaron la formación de federaciones indígenas en la Amazonía, en Madre de Dios, los dominicos vieron a FENAMAD como un desafío a su papel mediador y se opusieron desde su inicio. ${ }^{8}$ A mediados de la década de los ochenta, el sacerdote español de Shintuya, Ignacio Iraizoz, utilizó su control de la mano de obra en el aserradero y ganadería de la misión, así como su monopolio del suministro de gasolina, para evitar que los delegados indígenas asistieran a reuniones que FENAMAD convocaba en Puerto Maldonado. Los indígenas de Shintuya vieron así en FENAMAD la oportunidad de liberarse del sacerdote (Thomas Moore, comunicación personal). Además, en ausencia de un Estado central fuerte en Madre de Dios, las autoridades regionales (por ejemplo, jueces, policías y militares) se aliaron con los patrones mineros y representaron los intereses de estos. En los distritos y provincias más alejados de Puerto Maldonado,

8 Ver Morin (1992) y Salazar (1981) para estudios del papel de los misioneros católicos en la formación de federaciones étnicas en Perú y Ecuador. 
comerciantes y patrones eran elegidos alcaldes y miembros del concejo municipal, monopolizando los fondos públicos en su propio interés y los de los pequeños mineros y comunidades nativas que los respaldaban en las elecciones (Gray 1997: 84). FENAMAD representaba una alternativa a estos lazos clientelistas. Con el apoyo técnico y financiero del Centro Eori, una ONG fundada por Thomas Moore, la federación ayudó a varios asentamientos arakbut a obtener títulos de propiedad, ${ }^{9}$ a presentar numerosas demandas contra los abusos de mineros y autoridades y a obtener concesiones para depósitos de oro ubicados dentro de sus comunidades, una estrategia utilizada para detener el avance de colonos mineros hacia tierras indígenas (Pacuri y Moore 1992). Las redes con activistas por los derechos indígenas también fueron claves para que la federación obtuviera apoyo externo para lanzar una campaña que logró romper la oposición del Estado a la creación de la Reserva Comunal Amarakaeri y de una reserva para la protección de pueblos indígenas en aislamiento (FENAMAD 1993). ${ }^{10}$

La construcción de redes de alianza con antropólogos y ONG hizo posible que los arakbut pudieran no solo enfrentar las políticas estatales que los amenazaban, sino también sortear las estructuras de poder locales que los marginaban. Esto no quiere decir que las relaciones de los arakbut con los activistas siempre fueron armoniosas, ni que con el tiempo las ONG no intentarían llevar a los indígenas hacia relaciones de patronazgo. De hecho, los arakbut buscarían cada vez más la autonomía frente a los antropólogos y las ONG, y ejercer un mayor control de FENAMAD. Lo que quiero enfatizar aquí es que el papel de intermediación de los activistas de los derechos indígenas redujo las asimetrías de poder, permitiendo a los indígenas evitar relaciones potencialmente clientelistas con el Estado, sus aliados y los partidos políticos. Sin embargo, la organización política indígena en Madre de Dios no evolucionó hacia un mayor control indígena del Estado regional, que ha permanecido en manos de los mestizos más estrechamente identificados con los intereses de los mineros y las corporaciones petroleras.

9 Puerto Luz, por ejemplo, recibió en 1986 un título colectivo para 38784 hectáreas de tierras cultivables, además de la cesión en uso de 18089 hectáreas de bosque.

10 Los partidos políticos no representaban una alternativa al clientelismo con el Estado. Dominados por blancos y mestizos que a menudo se acercaban a los indígenas con actitudes racistas y autoritarias, los partidos políticos vieron la formación de federaciones indígenas en la Amazonía con sospecha y hostilidad, o en el mejor de los casos trataron de absorberlos y controlarlos (Smith 1996). Esta tendencia al autoritarismo y la cooptación generó entre los indígenas desconfianza hacia los partidos políticos. En este contexto, FENAMAD asumió el papel de partido político y trabajó como mediador entre los indígenas y el Estado. 


\section{Gubernamentalidad neoliberal: boom petrolero y clientelismo}

Una mañana, mientras recorría la comunidad de Puerto Luz, advertí la presencia de personas foráneas. El emblema que adornaba las gorras y camisas color caqui que llevaban puestas indicaba su conexión con Hunt Oil. Estaban paradas frente a la escuela, donde habían apilado varias cajas de cartón que contenían regalos de Navidad para los niños. Después de intercambiar saludos con los arakbut, Silvana Lay, la líder de los visitantes, entró a un salón de clase y habló a los niños sobre la importancia del petróleo y el gas natural para el desarrollo del país. Pero los niños parecían no entender el lenguaje especializado con el que se les hablaba. Algunos recibieron regalos si contestaban correctamente a las preguntas que Lay les hacía. "Hemos venido a premiarlos por un excelente año escolar", explicó mientras la filmaba su camarógrafo. Unas mujeres arakbut con niños pequeños en brazos se acercaron a pedir regalos, contentándose con gorras y globos. Más tarde, el equipo se dirigió hacia el local comunal, donde se reunió con autoridades y otros miembros de la comunidad. La reunión fue tensa. Los arakbut estaban enojados porque la compañía no había estado brindando asistencia a los enfermos ni había cubierto los gastos de viaje de varios arakbut que deseaban asistir a un festival de danza en Puerto Maldonado. El jefe de la comunidad, apoyado por algunos ancianos, exigió al personal de Hunt que atendiera sus pedidos de apoyo. Pero Lay no se dejaba persuadir fácilmente. Después de aclarar que la compañía no podía satisfacer todas las demandas de la comunidad, pues aún no estaba percibiendo ganancias, agregó: "Para reanudar nuestra asistencia, necesitamos que la comunidad firme un acuerdo dando su consentimiento al trabajo de Hunt en el territorio de Puerto Luz". El jefe aprovechó la situación y pidió a Lay que donara cerveza para las celebraciones del aniversario de la comunidad. "Usted está cordialmente invitada a quedarse para la fiesta y probar la comida local, si lo desea", añadió. Lay rechazó cortésmente la invitación, pero ofreció donar combustible para el generador eléctrico de la comunidad, no sin antes aclarar que, ante la falta de un acuerdo por escrito, su ofrecimiento era un gesto de buena voluntad.

Este evento es un ejemplo de cómo Hunt Oil recurría al patronazgo con el fin de contrarrestar la oposición de la comunidad a su proyecto de explotación petrolera, una táctica común entre las empresas petroleras multinacionales que planean realizar trabajos de prospección en territorios indígenas (Sawyer 2004). Hunt Oil canalizaba sus recursos en forma de bienes, servicios y regalos a cambio del consentimiento de la comunidad. Gran parte de estos recursos constituían, en realidad, la compensación que la compañía estaba legalmente obligada a proporcionar a las comunidades por los daños ambientales o pérdidas económicas que pudiera causar a sus tierras. Sin embargo, Hunt Oil publicitaba esta compensación como si fuera una muestra de su generosidad. ${ }^{11}$ Durante mi estadía en Puerto Luz, la corporación había accedido

11 Según la legislación peruana, una concesión petrolera le otorga a su titular el derecho de explorar y explotar los hidrocarburos que se encuentran en el subsuelo, pero no derechos sobre la superficie 
a compensar a la comunidad por el uso de sus tierras y los daños ecológicos y económicos causados por las líneas sísmicas abiertas durante sus actividades de prospección, varias de las cuales pasaban por las tierras de la comunidad. Esta compensación incluía un suministro mensual de gasolina para el generador eléctrico de la comunidad, materiales para la escuela y apoyo a los enfermos a través de campañas de salud y evacuaciones de emergencia a Puerto Maldonado o Cusco. Para fortalecer su imagen de benefactor, la compañía también entregaba regularmente obsequios a la comunidad, como juguetes y panetones durante las navidades, y transporte hacia Puerto Maldonado. La corporación también se propuso garantizar el consentimiento de la comunidad mediante la contratación e incluso soborno de líderes indígenas, de quienes se esperaba a cambio que persuadieran a otros miembros de sus comunidades para apoyar el proyecto de explotación petrolera de la empresa. Como resultado, algunas familias aceptaron la presencia de Hunt Oil siempre que proporcionara bienes y servicios a la comunidad.

Estas tácticas ciertamente funcionaron como una estrategia de "divide y reinarás" que generaba tensiones tanto al interior de las comunidades como entre ellas. La llegada de Hunt Oil a las comunidades de Shintuya y Puerto Luz dividió a sus miembros entre aquellos que apoyaban a la compañía petrolera y los que estaban en contra de ella. Esta división exacerbó las tensiones ya existentes entre los grupos de residencia.

En el momento de mi trabajo de campo en Puerto Luz, muchas de estas tensiones habían surgido de las asociaciones que algunos arakbut habían establecido con colonos mineros, que otros arakbut consideraban que amenazaban el control de la comunidad sobre su territorio. La desconfianza mutua y el conflicto resultantes entre los arakbut socavaron su capacidad para lograr la cohesión y organizar la resistencia colectiva a las operaciones de Hunt Oil. Una vez que el apoyo a la corporación ganó preeminencia entre la mayoría de sus miembros, tanto Shintuya como Puerto Luz rompieron su lealtad a FENAMAD. Exigieron el derecho a ser autónomos en sus decisiones y a negociar acuerdos con la empresa sin la mediación de la federación, engendrando la enemistad de aquellas comunidades que se resistieron a la empresa. El apoyo que algunas comunidades dieron a Hunt Oil también debilitó la campaña de FENAMAD contra la extracción de petróleo dentro de la Reserva Comunal Amarakaeri. En consecuencia, que la federación amenazara e incluso intentara varias veces desalojarla de la reserva no impidió que Hunt Oil continuara con sus actividades y abriera varios pozos exploratorios. Sin embargo, esto no significó que la federación y sus comunidades no fueran capaces de movilizarse para hacer frente a otras amenazas a sus derechos. Por ejemplo, en 2012 FENAMAD lideró

de la tierra. Cuando una concesión se superpone a tierras de propiedad de terceros, incluida una comunidad nativa, el titular de la concesión debe solicitar al propietario un acuerdo sobre la servidumbre (derecho de ocupación, de paso y de tránsito). Si no se llega a un acuerdo dentro de los 30 días, el Estado otorga la servidumbre y la compensación al propietario por el uso, daño y pérdida de ganancias. 
una exitosa movilización contra la interdicción de la extracción de oro dentro de las comunidades nativas.

Las relaciones de patronazgo entre Hunt Oil y algunas comunidades también afectaron la alianza entre indígenas y antropólogos. Como yo mismo pude experimentar, algunos indígenas, especialmente en las comunidades donde la corporación petrolera estaba operando, no estaban contentos con la idea de tener antropólogos metiendo sus narices en los asuntos de la comunidad. Dentro del clima de desconfianza que había generado la presencia de Hunt Oil, los antropólogos no eran necesariamente bienvenidos en las comunidades, lo que les dificultaba obtener el permiso de los jefes para realizar trabajo de campo en sus comunidades. Sin embargo, el deterioro de esta alianza era una consecuencia no solo de las condiciones actuales, sino también de una disminución en la necesidad de los indígenas de una mediación externa. El papel de puente desempeñado por FENAMAD, la participación indígena en la economía del oro y, más recientemente, las mejoras en la comunicación con Puerto Maldonado han renovado las conexiones entre comunidades nativas y entre éstas y el Estado. Además, los líderes de FENAMAD han creado sus propias redes que los vinculan a agencias de financiamiento globales y han adquirido conocimientos para gestionar por sí mismos proyectos o fondos para contratar asesores. En este nuevo contexto, los indígenas ya no dependen de la mediación de los antropólogos, que ahora tienen que negociar la posibilidad de hacer trabajo de campo en las comunidades. Más que mediadores, ahora los antropólogos son vistos como expertos que pueden ser contratados por los indígenas.

Uno de los factores que subyace a la vulnerabilidad de los arakbut al clientelismo son las décadas de políticas que han abierto las tierras indígenas en la Amazonía a las corporaciones transnacionales y han llevado a los pueblos indígenas a un empobrecimiento creciente. Si bien el impacto de estas políticas ya se sentía desde la década de los setenta, durante la administración de Alberto Fujimori (19902000) se emprendieron algunas de las reformas de reestructuración neoliberal más radicales. Uno de los componentes principales de las reformas de Fujimori fue la desregulación de las industrias extractivas y de los mercados de tierra. Reformas legislativas alentaron la inversión privada, especialmente transnacional, en la minería y la extracción de petróleo, y favorecieron las operaciones mineras a gran escala sobre la pequeña minería (Finer y Orta-Martínez 2010; Pacuri y Moore 1992). Al desmantelar los últimos vestigios de la reforma agraria de Velasco, el gobierno también facilitó el acceso de las corporaciones a tierras comunales. Una nueva ley de minería, por ejemplo, estipulaba que se podían otorgar concesiones mineras sobre tierras agrícolas. Estas nuevas políticas plantearon serias amenazas a los derechos territoriales indígenas, tales como un aumento significativo en el número de concesiones y contratos para la exploración y explotación de petróleo en la Amazonía, la mayoría de los cuales se superponían al territorio de comunidades nativas (Finer y Orta-Martínez 2010). En Madre de Dios, corporaciones multinacionales como Mobil Oil y Hunt Oil, de Estados Unidos, y SAPET, de China, obtuvieron concesiones y 
emprendieron actividades de exploración sísmica en tierras de comunidades nativas, incluso sin el consentimiento de sus miembros. Al mismo tiempo, el régimen de Fujimori decretó la libre comercialización de oro y cerró el Banco Minero, dejando a los arakbut sin acceso a rendimientos superiores a los del mercado del oro y sin suministros mineros a precios subsidiados (Pacuri y Moore 1992).

Otras medidas de ajuste estructural implementadas durante el gobierno de Fujimori incrementaron la dependencia de los arakbut con respecto a la extracción de oro. El gobierno liberalizó la economía agrícola, reduciendo sustancialmente el gasto público en ese sector. Se suspendieron los créditos baratos, los subsidios, los servicios de extensión y otras formas de apoyo estatal a los productores rurales (Crabtree 2002). Estas reformas privaron a los arakbut de la oportunidad de diversificar su acceso al mercado y a fuentes de ingreso a través de la producción agrícola, que se mantuvo como una actividad de subsistencia. Por otro lado, la explotación forestal, la artesanía y otras actividades productivas no proporcionaban una alternativa a la minería aurífera como generadora de ingresos. Los bajos precios y la falta de carreteras que conectaran a las comunidades con los mercados aumentaban los costos de producción, lo que hacía que las artesanías y la extracción forestal no fueran actividades económicas atractivas. Además, como parte de sus paquetes de estabilización, Fujimori redujo drásticamente o eliminó los programas de salud, educación y servicios sociales, mientras que el desempleo y los precios al consumidor aumentaron dramáticamente. En este contexto, los arakbut se volvieron aún más dependientes de la extracción de oro que, impulsada por los altos precios del metal precioso durante los años noventa y la primera década del siglo XXI, proporcionó un nivel de diversificación de la base económica que funcionó como un amortiguador.

Los intentos de FENAMAD por promover el desarrollo económico en sus comunidades base resultaron insuficientes para ampliar la base de sustento de los indígenas. Durante gran parte de su existencia, el principal objetivo de la federación fue asegurar la protección legal de los territorios de sus comunidades base, mientras que la promoción del desarrollo recibió solo una importancia secundaria (FENAMAD 1993). La federación buscó proporcionar a las comunidades proyectos de desarrollo solo cuando estas, una vez que obtuvieron títulos de propiedad sobre sus tierras, comenzaron a exigir empleo, educación y atención médica. Sin embargo, los proyectos que la federación implementó para satisfacer estas demandas tuvieron poco impacto en las condiciones de vida de los indígenas (FENAMAD 1996). La mayor parte de los fondos que la federación pudo recaudar sirvió solo para implementar proyectos a pequeña escala -como la provisión de becas de estudios secundarios y universitarios para jóvenes indígenas, programas de salud y revitalización de la cultura indígenaque no lograron los objetivos previstos, tuvieron impactos a corto plazo o trajeron solo beneficios individuales (FENAMAD 2007). FENAMAD ha implementado solo unos pocos proyectos de desarrollo a gran escala, entre los cuales el Plan Karene y Wanamei fueron los más importantes. En la década de los noventa, bajo la premisa 
de que los precios cambiantes del oro no ofrecían a los arakbut una fuente estable de sustento, el Plan Karene tenía la intención de romper la dependencia de los arakbut de la extracción de oro mediante la promoción de fondos rotatorios para la crianza de animales menores. Pero el proyecto no logró garantizar la autonomía económica de los indígenas, quienes más bien se volvieron aún más dependientes de la minería aurífera y de los ingresos que proporcionaba (IWGIA, FENAMAD y DANIDA 1999). Wanamei, una agencia de ecoturismo comunitario cuyo propósito era promover el uso sostenible de la Reserva Comunal Amarakaeri a la vez que generaba ingresos para los indígenas, no pudo lograr beneficios significativos para ser distribuidos entre las comunidades, beneficiando solo a las familias que ofrecían servicios personales a los turistas (Valcuende del Río, Murtagh y Rummenhoeller 2012).

Si bien los proyectos de desarrollo implementados por FENAMAD no lograron satisfacer la creciente demanda de las comunidades por ingresos y servicios básicos, redefinieron la interacción entre la federación y sus bases. Se desarrollaron relaciones de patronazgo entre las comunidades y la federación, ya que las primeras a menudo condicionaron su lealtad a la segunda a la provisión de recursos. Esto fue en parte resultado de la competencia entre la federación y los dominicos por la distribución de recursos a las comunidades. Los misioneros ofrecieron a las comunidades harakbut instalaciones educativas, un programa de salud y proyectos de explotación forestal y ganadera. Las comunidades aprovecharon la rivalidad entre la federación y los misioneros, ofreciendo sus lealtades a quienes mostraran mayor capacidad para satisfacer sus necesidades (Gray 1997: 268). Con los años, la influencia de los dominicos decayó y su papel de proveedores de recursos a los indígenas fue asumido por antropólogos y ONG, y más tarde por la federación. FENAMAD, por ejemplo, se hizo más popular entre sus bases una vez que demostró su eficacia para obtener títulos de propiedad para las comunidades y resolver conflictos entre estas y foráneos (Gray 1986: 115).

A principios de la primera década del siglo XXI, sin acceso a subsidios estatales para la minería aurífera, los arakbut se vieron obligados a arrendar sus tierras a los colonos mineros para capitalizar sus operaciones. El arrendamiento de tierras también sirvió como una salida para los conflictos aún recurrentes con los mineros en ese momento. Los mineros arrendatarios, que son conocidos como "invitados", pagaban una renta semanal tanto a las familias arakbut como a la comunidad. Los arakbut y los colonos recurrieron a las relaciones de amistad y compadrazgo, y a la moral de reciprocidad que estos lazos sociales conllevan, para fortalecer su asociación. Conocida localmente como "regalías", la renta se convirtió en una importante fuente de ingresos para los arakbut. Unas pocas familias fueron capaces de utilizar las regalías como capital, lo que les permitió comprar nuevos equipos de minería y mejorar su productividad, rompiendo así la dependencia económica sobre sus invitados. Sin embargo, para la mayoría, las regalías continuaron siendo la principal fuente complementaria de ingresos o incluso la única. La renta también 
se convirtió en una importante fuente de fondos para las arcas comunales, los que se utilizaban principalmente para cubrir los gastos de los viajes continuos que los jefes de la comunidad debían hacer a Puerto Maldonado, o para organizar las celebraciones del aniversario de la comunidad. En San José del Karene, los invitados ayudaron a la comunidad a construir un camino que los arakbut habían solicitado sin éxito al municipio, mientras que en Boca Inambari parte de las regalías se distribuía entre los ancianos que carecían de apoyo familiar. Las relaciones con los invitados alcanzaron límites extremos en Barranco Chico, donde los arakbut alquilaron casi todas sus tierras a los invitados y se marcharon de la comunidad para vivir de sus rentas en centros urbanos. La interacción indígena con los colonos mineros pasó del conflicto abierto a la cooperación, que no degeneró en peonaje por deuda ya que los arakbut nunca trabajaron para sus invitados. Sin embargo, estas relaciones han actuado en contra de la construcción de solidaridad entre los miembros de las comunidades. Cuando, por temor a perder sus tierras comunales a manos de los invitados, los arakbut de Puerto Luz decidían expulsarlos de la comunidad, los beneficios económicos obtenidos de estos lazos sociales y las lealtades personales que engendraban socavaron todos los esfuerzos comunitarios para deshacerse de los invitados.

Sin embargo, una mayor dependencia de la minería aurífera hizo a los arakbut más vulnerables a la incertidumbre de los precios del oro y de las políticas estatales. De hecho, para el 2011, los yacimientos auríferos y su capacidad para proporcionar ingresos a los arakbut estaban en franca decadencia. En Puerto Luz, los yacimientos de oro casi se habían agotado, lo que coincidió con una caída del precio internacional del oro y con los esfuerzos del gobierno de Ollanta Humala (2011-2016) para erradicar la minería ilegal en Madre de Dios. El gobierno convirtió la extracción de oro sin la debida autorización en un delito penal y prohibió las operaciones mineras fuera de un corredor designado de 500000 hectáreas. Como las comunidades arakbut quedaron fuera de este corredor, la extracción de oro dentro de sus territorios se volvió ilegal. ${ }^{12}$ Como resultado, la mayoría de los invitados se marcharon, dejando a los arakbut con poco o ningún ingreso de las regalías. Por lo tanto, a fines del 2011 las relaciones con los invitados ya no producían los recursos que los arakbut necesitaban para enfrentar sus precarias condiciones de vida.

El efecto combinado de las políticas neoliberales, la limitada capacidad de FENAMAD para satisfacer la creciente demanda de recursos económicos de las comunidades y el decaimiento de la minería aurífera deterioraron las condiciones económicas de los arakbut y aumentaron su dependencia del apoyo externo. Si bien las comunidades arakbut ahora están más integradas y la federación ya no necesita del papel mediador de los foráneos, las comunidades aún dependen de 
las redes con actores externos para obtener los recursos que les permitan satisfacer sus necesidades. Esta situación proporcionó a Hunt Oil un terreno fértil para el desarrollo de relaciones clientelares con los arakbut. Además, con las comunidades marginadas de los recursos y del poder político, a Hunt Oil le resultó relativamente fácil usar su poder económico para crear dependencia entre los arakbut y asegurar su apoyo. A pesar de los esfuerzos de la compañía por mostrarse preocupada por el desarrollo social y económico de los pueblos indígenas de la región, la calidad de su asistencia social fue pobre y las mejoras introducidas en las condiciones de vida de las comunidades fueron poco significativas. Como resultado, la actividad petrolera no llevó inversión social a las comunidades arakbut. Puesto que el acceso a los recursos de Hunt Oil no mejoró sustancialmente la calidad de vida de los arakbut, la necesidad de más recursos se reprodujo, manteniendo así las relaciones de patronazgo con la empresa petrolera. Al proporcionar servicios básicos, empleo y bienes a las comunidades, la empresa asumió funciones que son convencionalmente responsabilidad de los organismos estatales. Pero el propósito de entregar estos recursos a los indígenas no era reducir la pobreza ni reconocer sus derechos, sino obtener acceso a los recursos hidrocarburíferos ubicados dentro de sus territorios.

Las condiciones materiales son sin duda una explicación necesaria pero no suficiente de la prevalencia del patronazgo en las relaciones de los arakbut con Hunt Oil. El patronazgo también se ve facilitado por las normas culturales harakbut que favorecen las relaciones paternalistas con el otro poderoso. En tiempos precoloniales, el liderazgo entre los pueblos de habla harakbut se basaba en dar muestras de habilidad y generosidad, que eran las fuentes de un poder no coercitivo (prestigio e influencia). En contextos coloniales, los harakbut han proyectado sus nociones tradicionales de liderazgo y poder hacia los foráneos, percibendo a misioneros, antropólogos y colonos mineros como líderes poderosos debido a que estos tenían acceso a recursos y habilidades que los harakbut necesitaban y querían aprovechar. Sin embargo, al igual que con los líderes tradicionales harakbut, el poder de los foráneos y la lealtad de sus seguidores dependen de la continuidad de su eficacia para obtener recursos y de mostrar generosidad en su distribución a las comunidades. La corporación petrolera aprovechó estos patrones culturales para llevar a cabo sus tácticas clientelistas, a menudo alentando la competencia con FENAMAD y minimizando la capacidad de esta para satisfacer las necesidades de los indígenas, de la misma manera que la federación compitió con los dominicos por la lealtad de las comunidades hace algunas décadas. En este contexto, algunos harakbut enmarcaron su decisión de apoyar a Hunt Oil dentro del lenguaje de la reciprocidad. Como me dijo el jefe de Puerto Luz:

Los dirigentes de FENAMAD solo vienen aquí a decirnos que no aceptemos a la empresa. Dicen que cada comunero debe aportar al menos 100 soles para comprar gasolina. Pero lo que deberían decir es que van a implementar un proyecto para proporcionar a la comunidad electricidad o gasolina para nuestro generador eléctrico. 
Considérese también el caso de un wachiperi contratado por Hunt Oil como especialista en relaciones comunitarias. FENAMAD opinaba que la decisión de este wachiperi de trabajar para la compañía era una traición a la causa de los indígenas, pero él lo justificaba con el argumento de la falta de reciprocidad por parte de la federación. La hermana del wachiperi, que se oponía tenazmente a la explotación petrolera dentro de la reserva, me contó una conversación que tuvo con su hermano: "¿Por qué estás en contra de la compañía? ¿Qué te da FENAMAD? ¿Acaso te da trabajo?", la regañó. El patronazgo está hoy tan profundamente arraigado en la cultura de los peruanos que se ha convertido en la manera de hacer las cosas, impregnando todo tipo de interacción social, algo muy parecido a lo que Bourdieu llamó "habitus" (Bourdieu 1977).

Los patrones culturales de patronazgo se ven fortalecidos por la hegemónica retórica neoliberal de la agencia. A diferencia del peonaje por deudas con los misioneros, que se basó en el aislamiento de los indígenas y su necesidad de mediación, el predominio actual del clientelismo se beneficia de la idea neoliberal de entender a las corporaciones y comunidades como agentes equivalentes, autónomos y capaces de forjar conexiones en términos corporativos (Gershon 2011). El dinero es una tecnología neoliberal que funciona como un estándar universal que facilita la negociación entre actores de tamaño y poder muy desiguales. Al referirse a los \$ 380000 que Hunt Oil ofreció como compensación a la Reserva Comunal Amarakaeri, un representante de la empresa dijo: "Pueden usar ese dinero para vigilar la reserva contra la tala ilegal y la minería ... Somos una buena oportunidad para la reserva" (la traducción es mía) (Weinberg 2009: 8). El modelo de agencia neoliberal ve al ego como un actor de mercado que puede decidir de manera autónoma cómo relacionarse con otros actores, una perspectiva que parece reforzar el fuerte deseo de autonomía que caracteriza la socialidad indígena amazónica (Overing 1988). Aunque FENAMAD se formó para representar y defender los intereses de los pueblos indígenas de Madre de Dios, y para mediar su interacción con el Estado, las comunidades han reivindicado cada vez más su autonomía con respecto a la federación y el derecho de interactuar con la sociedad mayor sin mediación. En este contexto, Puerto Luz y Shintuya, en parte alentados por Hunt Oil, desdeñaron el papel representativo de FENAMAD y buscaron tratar con la compañía petrolera de manera directa. Como me explicó el presidente de Puerto Luz:

FENAMAD nunca se ha preocupado por las necesidades de las comunidades. Aunque es una federación, nuestro representante, FENAMAD nunca ha tratado de apoyarnos. Los dirigentes han criticado a la comunidad por aceptar a la compañía petrolera. Entonces, como comunidad autónoma, hemos tomado la decisión de dejar entrar a la empresa. Lo que no me gusta de FENAMAD es que se opone a la empresa independientemente de las necesidades de la comunidad. Nunca nos han enseñado cómo negociar un acuerdo con la empresa.

No solo las comunidades exigen autonomía. Como el expresidente del Ejecutor del Contrato de Administración (ECA) de la Reserva Comunal Amarakaeri 
me dijo una vez: "FENAMAD quiere controlar al ECA, pero el ECA es autónomo". Estas demandas de autonomía política facilitaron el acceso de Hunt Oil a las tierras indígenas, ya que fue mucho más fácil para la corporación petrolera negociar con las organizaciones indígenas de forma individual que tratar con el órgano representativo.

Los lazos de patrón-cliente coordinaron y consolidaron el gobierno en relación con la extracción de petróleo en Madre de Dios. Las relaciones clientelares tuvieron el efecto de modelar la conducta de los indígenas tanto individual como colectivamente. Restringidos por la deuda y la obligación moral de corresponder al patrón, las comunidades se abstuvieron de tomar medidas contra la compañía petrolera. Las tensiones que los lazos de patronazgo generaron en las familias y comunidades nativas neutralizaron cualquier acción coordinada que los pueblos indígenas pudieran emprender para oponerse a la empresa. La ruptura de la lealtad de las comunidades de Shintuya y Puerto Luz hacia FENAMAD y las comunidades que representa desmovilizaron la resistencia indígena al proyecto extractivo de Hunt Oil, lo que impidió que los indígenas expulsaran a la compañía petrolera de la reserva y de las tierras de las comunidades. La falta de empoderamiento de los pueblos indígenas en Madre de Dios sin duda socavó su capacidad para contrarrestar el poder del Estado y de Hunt Oil, lo que contribuyó a los esfuerzos por gobernar la región. Por lo tanto, en este caso Hunt Oil funcionó como un mecanismo para introducir la disciplina en una región rica en recursos naturales pero habitada por pueblos indígenas históricamente rebeldes que amenazan con detener la expansión del Estado y las corporaciones.

\section{Conclusión}

He examinado cómo los procesos complejos y dinámicos de formación del Estado han moldeado la movilización política entre los pueblos indígenas en el sureste del Perú. La historia de la región de Madre de Dios demuestra que las formas en que el pueblo arakbut se articuló con el Estado engendró relaciones sociales que tuvieron una influencia decisiva en las subjetividades políticas y formas organizativas indígenas. Los regímenes estatales que han dominado el país durante las últimas cinco décadas condicionaron diferentes estructuras sociales que han favorecido u obstaculizado la movilización política de los indígenas. Por lo tanto, la capacidad de los pueblos indígenas para defender sus territorios y medios de vida se ve determinada no tanto por la presencia o ausencia de una facultad indígena "inherente" para la acción colectiva, sino por su posición cambiante dentro de la estructura de poder más amplia. En este sentido, las estructuras estatales no se desarrollan a partir del capital social, dan forma al capital social (Tarrow 1996: 395).

He argumentado que las tecnologías de la gubernamentalidad neoliberal subyacen a las dificultades que enfrentó FENAMAD para detener la exploración petrolera dentro de los territorios indígenas. Las relaciones patrón-cliente entre Hunt Oil y las comunidades funcionaron como una técnica de gobierno que 
convierte a los indígenas en sujetos neoliberales que se disciplinan para cumplir con las políticas estatales. En línea con la retórica hegemónica de la subjetividad neoliberal, los indígenas reclaman autonomía y guían sus decisiones basados en los principios del mercado. Al actuar como clientes de la compañía petrolera, los indígenas se endeudan con ella y, por lo tanto, evitan la resistencia. La ruptura del papel mediador de FENAMAD que esto conlleva crea tensiones entre las bases de la federación, desmovilizando la campaña indígena contra la explotación petrolera. Sin embargo, al contrario de la retórica neoliberal de la libre elección, las políticas neoliberales que han agravado las condiciones de pobreza en la región obligan a los indígenas a negociar con la compañía petrolera como una forma de obtener acceso a los recursos de los que están estructuralmente marginados. El faccionalismo dentro de la FENAMAD, por tanto, no es un resultado de la incapacidad de los indígenas de construir capital social o de su caída de un estado original de comunitarismo. Es, más bien, el relacionamiento de los indígenas con las corporaciones a través de la racionalidad del mercado lo que, actuando como un mecanismo de autogobierno, ha inhibido cualquier respuesta colectiva a las relaciones de explotación a las que están sujetos los indígenas.

Este estudio de caso desafía la suposición común de que las relaciones de los indígenas con el Estado y las industrias extractivas se caracterizan ante todo por la "resistencia". He demostrado que las corporaciones transnacionales como formas de gubernamentalidad neoliberal tienen el poder de neutralizar la resistencia indígena, no con violencia sino con la creación de deuda. En este contexto, la política de los arakbut tiene implicaciones para una mayor comprensión de los movimientos indígenas en la Amazonía y potencialmente en otros contextos. Si se supone que una movilización indígena exitosa es contingente a la unidad entre las comunidades y entre ellas y sus líderes, la hegemonía actual de la gubernamentalidad transnacional y sus efectos divisivos en los países amazónicos representan un gran desafío para las luchas indígenas. La gubernamentalidad neoliberal, sin embargo, no es aceptada a pie juntillas. Si bien sus recientes compromisos con las industrias extractivas representan una imagen sombría para los arakbut, la historia de Madre de Dios muestra que las mismas fuerzas globales que elevaron a las corporaciones petroleras al estatus de cuasi-Estados han permitido a los pueblos indígenas construir redes que desafiaron las afirmaciones estatales de soberanía sobre sus territorios.

Agradecimientos. La investigación en la que se basa este artículo fue generosamenteapoyada por Inter-AmericanFoundation(Inter-American Foundation Grassroots Development Fellowship), University of Florida (John M. Goggin Award) y Centre National de la Recherche Scientifique (Bourse du Legs Lelong). Agradezco a Thomas Moore, Enrique Mayer, Michael Brown, John Donaldson, Everett Frost y Stéphanie Borios por sus valiosos comentarios y sugerencias, los que contribuyeron a mejorar el manuscrito. Una versión anterior de este artículo fue publicada en el 2017 en Journal of Latin American and Caribbean Ethnic Studies. 


\section{Referencias bibliográficas}

Babidge, Sally.

2013 ''Socios': the contested morality of 'partnerships' in indigenous community-mining company relations, northern Chile". En: The Journal of Latin American and Caribbean Anthropology 18: 274-293.

Baitenmann, Helga.

2005 "Counting on state subjects: state formation and citizenship in twentiethcentury Mexico". En: Krohn-Hansen, Christian y Nustad, Knut G. (ed.), State formation: anthropological perspectives. London: Pluto Press, pp. 171-194.

Bebbington, Anthony.

1997 "Social capital and rural intensification: Local organizations and islands of sustainability in the rural Andes". En: The Geographical Journal 163, n. ${ }^{\circ}$ : 189-197.

Bebbington, Anthony y Perreault, Thomas.

1999 "Social capital, development, and access to resources in highland Ecuador". En: Economic Geography 75, n. ${ }^{\circ}$ 4: 395-418.

Bourdieu, Pierre.

1977 Outline of a theory of practice. Cambridge: Cambridge University Press.

1986 "The forms of capital". En: Richardson, J. (ed.), Handbook of theory and research for the sociology of education. Westport: Greenwood, pp. 241-258.

Brysk, Alison.

2000 From tribal village to global village: Indian rights and international relations in Latin America. Stanford: Stanford University Press.

Coleman, James S.

1988 "Social capital in the creation of human capital". En: The American Journal of Sociology 94: S95-S120.

Cotler, Julio.

1969 "Actuales pautas de cambio en la sociedad rural del Perú". En: Matos Mar, José y Whyte, William F. (eds.), Dominación y cambios en el Perú rural: La microregión del valle de Chancay. Lima: Instituto de Estudios Peruanos, pp. 60-79.

Crabtree, John.

2002 "The impact of neo-liberal economics on Peruvian peasant agriculture in the 1990s". En: Journal of Peasant Studies 29, n. ${ }^{\circ}$ 3: 131-161. 
Das, Veena y Poole, Deborah.

2004 "State and its margins: Comparative ethnographies". En: Das, Veena y Poole, Deborah (eds.), Anthropology in the margins of the state. Santa Fe: School of American Research Press, pp. 3-33.

Dean, Bartholomew.

2002 "State power and indigenous peoples in the Peruvian Amazon: A lost decade, 1990-2000". En: Maybury-Lewis, David (ed.), The politics of ethnicity: Indigenous peoples in Latin American states. Cambridge: Harvard University Press, pp. 199-237.

FENAMAD (Federación Nativa del Río Madre de Dios y Afluentes).

1993 "Conclusiones del VIII congreso". En: Avance Indígena 3, n. ${ }^{\circ}$ 4: 3-12.

FENAMAD (Federación Nativa del Río Madre de Dios y Afluentes).

1996 “Conclusiones del IX congreso". En: Avance Indígena 5, n. ${ }^{\circ}$ 8: 6-16.

FENAMAD (Federación Nativa del Río Madre de Dios y Afluentes).

2007 "25 años de lucha y reivindicación indígena: Trayectoria de FENAMAD". En: Avance Indigena 15: 6-15.

Ferguson, James y Gupta, Akhil.

2002 "Spatializing states: Toward an ethnography of neoliberal governmentality". En: American Ethnologist 29, n. ${ }^{\circ}$ 4: 981-1002.

Fine, Ben.

1999 "The developmental state is dead-long live social capital?". En: Development and Change 30, n. ${ }^{\circ}$ 1: 1-19.

Finer, Matt y Orta-Martínez, Martí.

2010 "A second hydrocarbon boom threatens the Peruvian Amazon: Trends, projections, and policy implications". En: Environmental Research Letters 5, n. ${ }^{\circ} 1$ <http:/ /10.1088/1748-9326/5/1/014012>

Foucault, Michel.

1991 "Governmentality". En: Graham Burchell, Gordon, Colin y Miller, Peter (eds.), The Foucault effect: Studies in governmentality. Chicago: The University of Chicago Press, pp. 87-104.

Fox, Jonathan.

1996 "How does civil society thicken? The political construction of social capital in Mexico". En: World Development 24, n. ${ }^{\circ}$ 6: 1089-1103.

Fuentes, Aldo.

1982 Parentesco y relaciones de producción en una comunidad harakmbut en el sur-oriente peruano. Documento no publicado, Centro Amazónico de Antropología y Aplicación Práctica. 
García, Alfredo.

2003 "FENAMAD 20 años después: apuntes sobre el movimiento indígena amazónico en Madre de Dios". En: Huertas, Beatriz y García, Alfredo (eds.), Los pueblos indígenas de Madre de Dios: Historia, etnografía y coyuntura. Lima: Grupo Internacional de Trabajo sobre Asuntos Indígenas, pp. 274-309.

Gershon, Ilana.

2011 “'Neoliberal agency.'”. En: Current Anthropology 52 n. ${ }^{\circ} 4$ : 537-555.

Granovetter, Mark S.

1973 "The strength of weak ties". En: American Journal of Sociology 78, n. . 6: 1360-1380.

Gray, Andrew.

1986 And After the Gold Rush...? Human rights and self-development among the Amarakaeri of southeastern Peru. Copenhagen: International Work Group for Indigenous Affairs.

1996 The Arakmbut: Mythology, spirituality, and history in an Amazonian community. Providence: Berghahn Books.

1997 Indigenous rights and development: Self-determination in an Amazonian community. Providence: Berghahn Books.

Greene, Shane.

2006 "Getting over the Andes: The geo-eco-politics of indigenous movements in Peru's twenty-first century empire". En: Journal of Latin American Studies 38, n. $^{\circ}$ 2: 327-354.

Gupta, Akhil.

1995 "Blurred boundaries: The discourse of corruption, the culture of politics and the imagined state". En: American Ethnologist 22, n. ${ }^{\circ} 2: 375-402$.

Harriss, John y Renzio, Paolo de.

1997 "'Missing link' or analytically missing?: The concept of social capital”. En: Journal of International Development 9, n. ${ }^{\circ}$ 7: 919-937.

Holzner, Claudio A.

2004 "The end of clientelism? Strong ties and weak networks in a Mexican squatter movement". En: Mobilization: An International Quarterly 9, n. ${ }^{\circ} 3$ : 223-240.

IWGIA (International Work Group for Indigenous Affairs), FENAMAD (Federación Nativa del Río Madre de Dios y Afluentes), y DANIDA (Danish International Development Agency).

1999 Informe de evaluación proyecto Plan Karene, Madre de Dios. Documento no publicado, International Work Group for Indigenous Affairs. 
Krohn-Hansen, Christian y Nustad, Knut G.

2005 "Introduction". En: Krohn-Hansen, Christian y Nustad, Knut G. (eds.), State formation: Anthropological perspectives. London: Pluto Press, pp. 3-26.

Landolt, Patricia y Portes, Alejandro.

1996 "The downside of social capital". En: The American Prospect 7, n. ${ }^{\circ}$ 26: 18-21.

Lemke, Thomas.

2001 "'The birth of bio-politics': Michel Foucault's lecture at the Collège de France on neo-liberal governmentality". En: Economy and Society 30, n. ${ }^{\circ} 2$ : 190-207.

Lowenthal, Abraham.

1975 "Peru's ambiguous revolution". En: Lowenthal, Abraham (ed.), The Peruvian experiment: Continuity and change under military rule. Princeton: Princeton University Press, pp. 3-43.

McNeill, Desmond.

2007 "Social capital or sociality? Methodological contrasts between economics and other social sciences". En: Ioannides, Stavros y Nielsen, Klaus (eds.), Economics and the social sciences. Northampton: Edward Elgar, pp. 163-184.

Moore, Thomas.

1979 "SIL and a 'new-found tribe': The Amarakaeri experience". En: Dialectical Anthropology 4, n. ${ }^{\circ}$ 2: 113-125.

Moore, Thomas.

1983 "Situación de los nativos frente a la minería aurífera en Madre de Dios". En: Shupihui 28: 413-426.

Morin, Françoise.

1992 "Les premiers congrès Shipibo-Conibo dans le contexte politique et religieux des années 60-70". En: Journal de la Société des Américanistes 78, n..$^{\circ}$ 2: 59-77.

Mosse, David.

2006 "Collective action, common property, and social capital in south India: An anthropological commentary". En: Economic Development and Cultural Change 54, n. ${ }^{\circ}$ 3: 695-724.

Narayan, Deepa.

1999 Bonds and bridges: Social capital and poverty. Washington, DC.: The World Bank.

Overing, Joanna.

1988 "Personal autonomy and the domestication of the self in Piaroa society". En: Jahoda, Gustav y Lewis, I. M. (eds.), Acquiring culture: Cross cultural Studies in child development. London: Routledge, pp. 169-192. 
Pacuri, Felipe y Moore, Thomas.

1992 Los conflictos entre mineros auríferos y el pueblo arakmbut en Madre de Dios, Perú. Documento no publicado, Centro Eori de Investigación y Promoción Regional.

Perreault, Thomas..

2003 "Social capital, development, and indigenous politics in Ecuadorian Amazonia". En: The Geographical Review 93, n. ${ }^{\circ}$ 3: 328-349.

Pinedo, Danny.

2014 The politics of sociality: Social networks and indigenous mobilization in Peruvian Amazonia. Tesis de doctorado, University of Florida. Gainesville.

2019 "Trazando fronteras: La producción de territorios indígenas en la Amazonía peruana". En: Bulletin de l'Institut Français d'Études Andines 48, n. ${ }^{\circ}$ 1: 21-37.

Putnam, Robert D., Leonardi, Robert y Nanetti, Rafaella Y.

1993 Making democracy work: Civic traditions in modern Italy. Princeton: Princeton University Press.

Rose, Nikolas.

1996 "Governing 'advanced' liberal democracies". En: Barry, Andrew; Osborne, Thomas y Rose, Nikolas (eds.), Foucault and political reason: Liberalism, neoliberalism and rationalities of government. Chicago: The University of Chicago Press, pp. 37-64.

Rosengren, Dan.

2003 "The collective self and the ethnopolitical movement: 'Rhizomes' and 'taproots' in the Amazon". En: Identities: Global Studies in Culture and Power 10, n. $^{\circ}$ 2: $221-240$.

Rubenstein, Steven.

2001 "Colonialism, the Shuar federation, and the Ecuadorian state". En: Environmental and Planning D 19, n. ${ }^{\circ}$ 3: 263-294.

Rummenhoeller, Klaus; Cárdenas, Clara y Lazarte, María.

1991 Diagnóstico situacional de comunidades nativas de Madre de Dios: propuestas para un autodesarrollo. Lima: Instituto Indigenista Peruano.

Salazar, Ernesto.

1981 "The federation Shuar and the colonization frontier". En: Whitten, Norman

E. Jr. (ed.), Cultural transformations and ethnicity in modern Ecuador. Urbana:

University of Illinois Press, pp. 589-613.

Sawyer, Suzana.

2004 Crude chronicles: Indigenous politics, multinational oil, and neoliberalism in Ecuador. Durham: Duke University Press. 
Scott, James C.

1998 Seeing like a state: How certain schemes to improve the human condition have failed. New Haven: Yale University Press.

Smith, Richard Chase.

1996 "Las políticas de la diversidad: COICA y las federaciones étnicas de la Amazonía". En: Varese, Stefano (ed.), Pueblos indios, soberanía y globalismo. Quito: Abya-Yala, pp. 81-125.

Tarrow, Sidney.

1996 "Making social science work across space and time: A critical reflection on Robert Putnam's Making Democracy Work". En: American Political Science Review 90, n. ${ }^{\circ}$ 2: 389-397.

Torralba, Adolfo.

1979 “Los harakmbut: nueva situación misionera". En: Antisuyo 3: 83-141.

Valcuende del Río, José María; Murtagh, Chantelle y Rummenhoeller, Klaus.

2012 "Turismo y poblaciones indígenas: espacios, tiempos y recursos". En: Scripta Nova: Revista Electrónica de Geografía y Ciencias Sociales 16. $<$ http://www.ub.edu/geocrit/sn/sn-410.htm>

Veber, Hanne.

1998 "The salt of the montaña: Interpreting indigenous activism in the rain forest". En: Cultural Anthropology 13, n. ${ }^{\circ}$ 3: 382-413.

Wahl, Lissie.

1987 Pagans into christians: The political economy of religious conversion among the Harakmbut of lowland southeastern Peru, 1902-1982. Tesis doctoral, The City University of New York. New York.

Weinberg, Bill.

2009 "Peru: Hunt Oil contract to reignite Amazon uprising?". En: NACLA Report of the Americas 42, n. ${ }^{\circ}$ 6: 6-9.

Weingrod, Alex.

1968 "Patrons, patronage, and political parties". En: Comparative Studies in Society and History 10, n. ${ }^{\circ}$ 4: 377-400.

Yashar, Deborah J.

2005 Contesting citizenship: The rise of indigenous movements and the postliberal challenge. Cambridge: Cambridge University Press. 